\title{
Perspective
}

\section{Kv1.3: a potential pharmacological target for diabetes}

\author{
Bok Hee $\mathrm{CHOI}^{1}$, Sang June $\mathrm{HAHN}^{2, *}$ \\ ${ }^{1}$ Department of Pharmacology, Institute for Medical Science, Chonbuk National University Medical School, Jeonju, Jeonbuk 561-180, \\ Korea; ${ }^{2}$ Department of Physiology, Medical Research Center, College of Medicine, The Catholic University of Korea, Seoul 137-701, \\ Korea
}

$\mathrm{K}^{+}$channels, which are ubiquitous membrane proteins, play a central role in regulating the resting membrane potential and the shape and duration of the action potential in pancreatic $\beta$-cells. There are at least three types of $\mathrm{K}^{+}$channels $\left(\mathrm{K}_{\mathrm{ATP}}, \mathrm{K}_{\mathrm{Ca}}\right.$, and $\mathrm{Kv2.1}$ channels) that are involved in glucose-stimulated insulin secretion in pancreatic $\beta$-cells, and one type (Kv1.3) that is associated with the regulation of insulin sensitivity in peripheral target tissues. This article reviews the function of Kv1.3 channels that contribute to mediating insulin action in insulin-sensitive tissues. Pharmacological strategies for targeting Kv1.3 are then discussed with a focus on a rationale for the potential therapeutic use of Kv1.3 blocker in diabetic treatment.

Keywords: Kv1.3; K+ channels; diabetes; insulin; rosiglitazone

Acta Pharmacologica Sinica (2010) 31: 1031-1035; doi: 10.1038/aps.2010.133; published online 16 Aug 2010

$\mathrm{K}^{+}$channels are membrane-integral proteins composed of differing combinations of pore-forming a-subunits and peripheral $\beta$-subunits. Thus far, more than $80 \mathrm{~K}^{+}$channel genes have been cloned. Five functional classes of $\mathrm{K}^{+}$channels have been defined on the basis of their topological arrangements and gating mechanisms: voltage-gated $\mathrm{K}^{+}$channels ( $\mathrm{Kv}$ channels), $\mathrm{Ca}^{2+}$ activated $\mathrm{K}^{+}$channels ( $\mathrm{K}_{\mathrm{Ca}}$ channels), ATP-sensitive $\mathrm{K}^{+}$ channels ( $\mathrm{K}_{\text {ATP }}$ channels), inwardly rectifying $\mathrm{K}^{+}$channels and two-pore domain $\mathrm{K}^{+}$channels ${ }^{[1,2]} \cdot \mathrm{K}^{+}$channels are ubiquitous in a variety of cells: neurons, cardiac myocytes, skeletal muscles, smooth muscles, pancreatic $\beta$-cells, lymphocytes and tumor cells $s^{[2-5]}$. Traditionally, $\mathrm{K}^{+}$channels play an important role in regulating cell excitability. For example, in excitable cells, they contribute to maintaining the resting membrane potential, to determining the shape and duration of action potentials and to modulating neurotransmitter release ${ }^{[1]}$. In non-excitable cells, however, $\mathrm{K}^{+}$channels regulate cell volume, cell differentiation and proliferation, apoptosis, and several other physiological functions ${ }^{[5]}$. The alteration of $\mathrm{K}^{+}$channel activity and expression can cause profound pathophysiological events in many different cell types. Thus, pharmacological agents that interact with $\mathrm{K}^{+}$channels can lead to beneficial therapeutic or untoward side effects.

\footnotetext{
* To whom correspondence should be addressed.

E-mail sjhahn@catholic.ac.kr

Received 2010-04-29 Accepted 2010-07-16
}

\section{$K_{A T P}, K_{C a}$, and $K v 2.1$ channels in insulin secretion}

There are at least three types of $\mathrm{K}^{+}$channels that are involved in glucose-stimulated insulin secretion in pancreatic $\beta$-cells ${ }^{[6]}$. First, there are the $\mathrm{K}_{\text {ATP }}$ channels, which have been implicated in the regulation of glucose homeostasis. $\mathrm{K}_{\mathrm{ATP}}$ channels are composed of four pore-forming Kir6 subunits and four regulatory subunits of sulfonylurea receptor ${ }^{[7]}$. These channels are known to be critical for setting the resting membrane potential of pancreatic $\beta$-cells and are regulated by the intracellular concentrations of ATP and ADP which have opposing effects on $\mathrm{K}_{\text {ATP }}$ channels ${ }^{[8]}$. After the characterization of $\mathrm{K}_{\text {ATP }}$ channels in pancreatic $\beta$-cells, it is reported that $\mathrm{K}_{\mathrm{ATP}}$ channel blockers modulate the release of insulin. Sulphonylurea drugs are currently being used in the treatment of type 2 diabetes $^{[9]}$. The primary pharmacological action of sulphonylurea is the block of the $\mathrm{K}_{\mathrm{ATP}}$ channels in the $\beta$-cells plasma membrane. This drug then depolarizes the membrane potential of $\beta$-cells by reducing the outward $\mathrm{K}^{+}$currents, which induces insulin secretion.

A second type of $\mathrm{K}^{+}$channels in pancreatic $\beta$-cells includes the $\mathrm{K}_{\mathrm{Ca}}$ channels, which activate in response to a rise in intracellular $\mathrm{Ca}^{2+}$ concentrations ${ }^{[10]}$. Although $\mathrm{K}_{\mathrm{Ca}}$ channels regulate the relationships between membrane potential and intracellular $\mathrm{Ca}^{2+}$ influx, which is the major determinant in exocytosis, the role of $\mathrm{K}_{\mathrm{Ca}}$ channels in glucose-stimulated insulin release is not well understood. Low concentrations of TEA and charybdotoxin, which inhibit $\mathrm{K}_{\mathrm{Ca}}$ channels, have no effect either on the membrane potential of $\beta$-cells or on insulin release from 
isolated islets ${ }^{[11]}$. These results suggest that $\mathrm{K}_{\mathrm{Ca}}$ channels are not the target on which glucose acts to regulate electrical activity and insulin release in pancreatic $\beta$-cells, although the exact role of $\mathrm{K}_{\mathrm{Ca}}$ channels in insulin secretion remains controversial. The third type of $\mathrm{Kv}$ channels can be divided into four conserved gene families, comprising the Kv1-4 (Shaker, Shab, Shaw, Shal-type subunits). In pancreatic $\beta$-cells, a number of different $\mathrm{Kv}$ channel subunits, Kv1.4, Kv1.6, Kv2.1, and Kv3.2, are expressed ${ }^{[4]}$. In addition, Kv1.5 is highly expressed in human insulinoma ${ }^{[12]}$. The Kv2.1, Shab-type Kv channel, is the primary $\mathrm{Kv}$ channel and is highly expressed in pancreatic $\beta$-cells. This channel mediates the majority of repolarizing delayed rectifier $\mathrm{K}^{+}$currents in pancreatic $\beta$-cells. The dominant negative knockout of Kv2.1decreased delayed rectifier $\mathrm{K}^{+}$ currents by about $60 \%$ and caused a much larger enhancement of glucose-stimulated insulin secretion in isolated rat islets ${ }^{[4]}$. Hanatoxin, a specific Kv2.1 inhibitor, increased the membrane potential and the intracellular $\mathrm{Ca}^{2+}$ oscillation response of insulin secreting cells to glucose, and enhanced insulin secretion from $\beta$-cells in a glucose-dependent manner ${ }^{[13]}$. These results suggest that $\mathrm{Kv} 2.1$ may represent a novel target for the treatment of type 2 diabetes.

\section{Kv1.3 in insulin sensitivity}

The Kv1.3 channel is a Shaker-type, delayed-rectifier $\mathrm{K}^{+}$channel and was originally identified in $\mathrm{T}$ lymphocytes as an $n$-type $\mathrm{K}^{+}$channel. Kv1.3 is involved in T-lymphocyte activation and proliferation by regulating membrane potential and $\mathrm{Ca}^{2+}$ signaling pathways ${ }^{[3]}$. This channel is expressed in many tissues, including lymphocytes, CNS, kidney, osteoclasts, testis and insulin-sensitive tissues such as adipose tissue, liver and skeletal muscle ${ }^{[14,15]}$. The Kv1.3 channel has been implicated in the regulation of a wide range of physiological functions, including cell volume regulation, cell proliferation and apoptosis in non-excitable cells, and neurotransmitter release and neuronal excitability in excitable cells. Several lines of evidence indicate that Kv1.3 may participate in the pathways that regulate energy homeostasis and body weight. For instance, Kv1.3 channels are expressed in postganglionic sympathetic neurons and influence the function of sympathetic activity that regulates body weight and energy homeostasis ${ }^{[16]}$. The genetargeted deletion of Kv1.3 in a genetic model of obese mice reduced adiposity and total body weight by increasing locomotor activity and thereby total energy expenditure without changing blood glucose and insulin levels ${ }^{[17]}$. In addition, mice bearing a disrupted Kv1.3 gene had a lower body weight and an increased basal metabolic rate which made them resistant to diet-induced obesity ${ }^{[14]}$. Although the exact mechanism by which Kv1.3 regulates energy homeostasis is not understood yet, these results highlight the Kv1.3 channels as an important component of the pathways that regulate body weight and energy homeostasis and as a potential target for the development of the drug in the management of obesity.

Insulin signaling systems have been shown to be involved in the regulation of food intake and body weight ${ }^{[18]}$. The potential phosphorylation site for tyrosine kinase has been identified in Kv1.3 channels and tyrosine phosphorylation has been linked to the regulation of the activity of Kv1.3 in the olfactory bulb neurons ${ }^{[19]}$. These findings suggest that the functional linkage between Kv1.3 and insulin receptor has been implicated in insulin signaling. Indeed, a polymorphism in the human Kv1.3 gene is associated with decreased insulin sensitivity and impaired glucose tolerance but not with insulin secretion, suggesting a candidate gene for the pathogenesis of insulin resistance ${ }^{[15]}$. Another mechanistic study showed that Kv1.3 gene deletion and channel inhibition enhanced peripheral insulin sensitivity by increasing the amount of glucose transporter 4 (GLUT4) at the plasma membrane and the uptake of glucose in skeletal muscle and adipose tissue via intracellular $\mathrm{Ca}^{2+}$ signaling ${ }^{[20,21]}$. Therefore, these results indicated that Kv1.3 may play a critical role in insulin action by controlling peripheral insulin sensitivity, although this channel is not associated with insulin secretion in pancreatic $\beta$-cells. Furthermore, it is reported that long-term treatment of fluoxetine, a selective serotonin reuptake inhibitor, is associated with a reduction in food intake and body weight and seems to improve insulin sensitivity, possibly by an increase in glycogen synthase activity in skeletal muscle tissue ${ }^{[22]}$. Although the mechanism mediating this effect is unknown, the fact that fluoxetine potently blocks Kv1.3 may lead to the hypothesis that increased insulin sensitivity may be attributed to the inhibitory effect of this drug on Kv1.3 ${ }^{[23]}$. The role of Kv1.3 in insulin sensitivity is summarized in Figure 1. Although Kv channel blockers are currently used for several diseases, recent studies have spotlighted Kv1.3 as a potential therapeutic target for treatment of autoimmune disease, type 2 diabetes, asthma, aplastic anemia and periodontal disease ${ }^{[24-28]}$.

\section{Kv1.3 as a potential drug target in diabetic therapy}

Type 2 diabetes is a metabolic disease, mainly caused by pancreatic $\beta$-cell dysfunction and insulin resistance in the peripheral target tissues. Thiazolidinedione derivatives are widely used in the management of type 2 diabetes as an insulin sensitizer. Although the mechanism of action for thiazolidinedione derivatives is not completely understood, it is well recognized that they do not directly stimulate insulin secretion from pancreatic $\beta$-cells but the binding of these drugs to peroxisome proliferator-activated receptor- $\gamma\left(\mathrm{PPAR}_{\gamma}\right)$ enhances the expression of the glucose transporter and increases insulin sensitivity in target tissues such as, adipose tissue and skeletal muscle ${ }^{[29]}$. Our recent study showed that rosiglitazone and troglitazone, thiazolidinedione derivatives, potently blocked Kv1.3 in a concentration-dependent manner (Figure 2) ${ }^{[30]}$. Because the pharmacological regulation of Kv1.3 may be an important mechanism mediating insulin sensitivity as described previously, these results suggest that besides activation of $\mathrm{PPAR}_{\gamma}$, part of the increased peripheral insulin sensitivity promoted by these drugs may be mediated through the inhibition of Kv1.3 channel activity. From these results, thiazolidinedione derivatives can be used in the treatment of diabetes as a new paradigm of a combination effect involving conventional pharmacological actions and $\mathrm{K}^{+}$channel-blocking properties. 


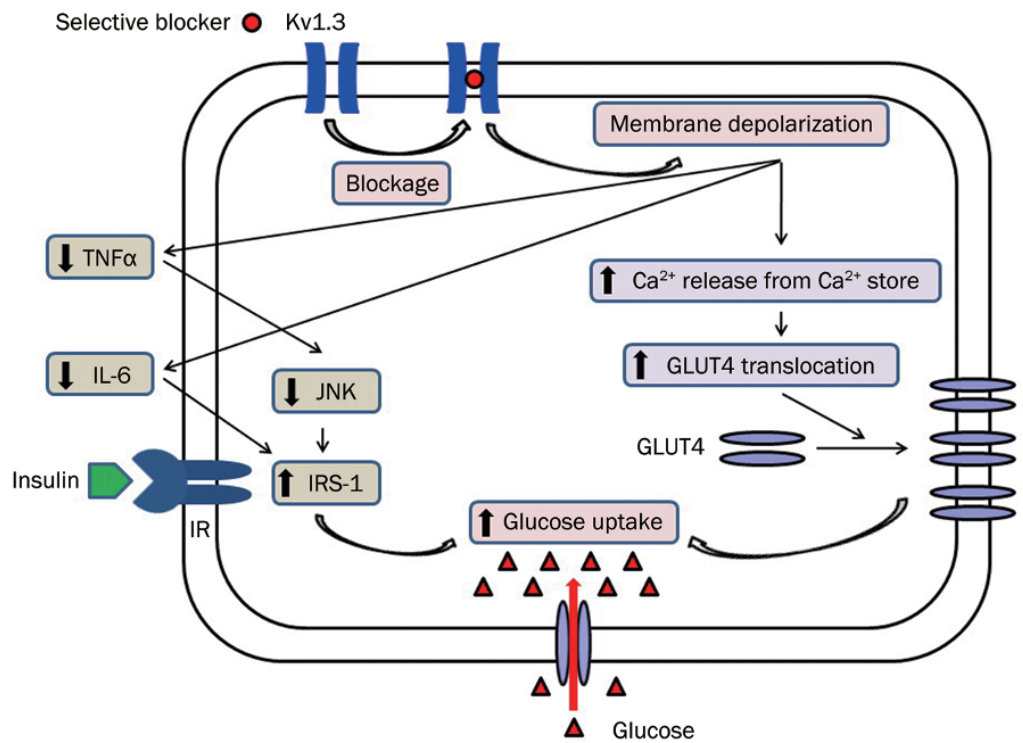

Figure 1. A cellular mechanism for Kv1.3-involved glucose uptake in insulin-sensitive cells. IR, insulin receptor; IRS-1, insulin receptor substrate-1; GLUT4, glucose transporter 4; TNF $\alpha$, tumor necrosis factor $\alpha$; JNK, c-JUN terminal kinase; IL-6, interleukin-6; up and down arrows, increased and decreased activities, respectively.
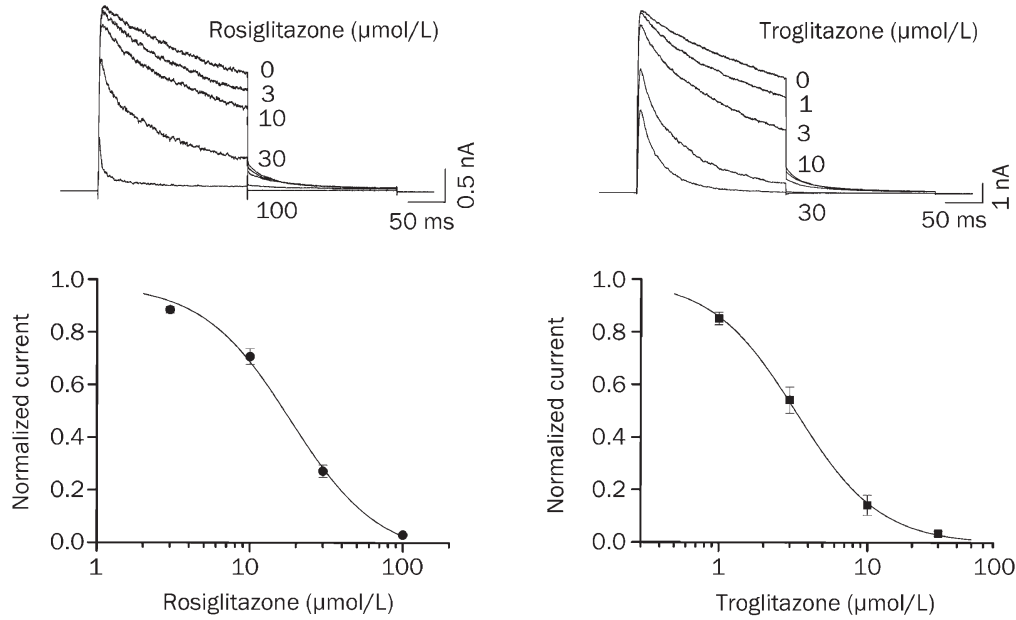

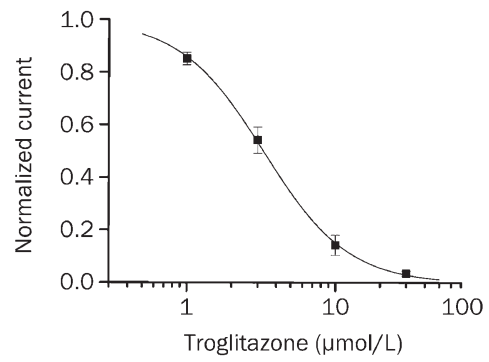

Figure 2. Concentration-dependent inhibition of Kv1.3 currents expressed in $\mathrm{CHO}$ cells by rosiglitazone and troglitazone. Superimposed currents were elicited by applying a 200-ms depolarizing pulse from a holding potential of -80 $\mathrm{mV}$ to $+40 \mathrm{mV}$ every $30 \mathrm{~s}$ in the absence and presence of different concentrations of drugs. Concentration-response curves for the inhibition of Kv1.3 currents. The druginduced inhibition were measured at the end of a 200-ms depolarizing pulse of $+40 \mathrm{mV}$ and were normalized to the current under control conditions. The normalized currents were fitted to the Hill equation $(n=7-8)$. Data are expressed as means $\pm \mathrm{SEM}^{[30]}$.
$\mathrm{K}^{+}$channels are the most diverse family of ion channels and contribute to many important physiological functions in various tissues. Thus, $\mathrm{K}^{+}$channel blocker, as an ideal and safe therapeutic drug, should act selectively and potently on the specific target $\mathrm{K}^{+}$channels without affecting other ion channels. However, most drugs currently used in clinics display variable effects on several ion channels, which can cause undesirable cardiovascular side effects, especially when blocking cardiac ion channels. Since several $\mathrm{K}^{+}$channels are involved in insulin release and actions as described above, a drug that acts on more than a single ion channel could be more effective in the treatment of type 2 diabetes. For instance, thiazolidinedione derivatives not only inhibit Kv1.3 but also $\mathrm{K}_{\text {ATP }}$ channel activities $^{[30,31]}$, which provide evidence for a dual mechanism underlying hypoglycemic action of this drug: 1) increased peripheral insulin sensitivity of target tissues, and 2) increased insulin secretion in pancreatic $\beta$-cells. Thus, a potential combined therapeutic effect might be expected from the blocking properties of drugs on Kv1.3, Kv2.1, and $\mathrm{K}_{\text {ATP }}$ channels.
Additionally, the inflammatory cytokines such as interleukin-6 (IL-6) and tumor necrosis factor-a (TNFa) have been known to play an important role in insulin resistance ${ }^{[32,33]}$. IL-6 exerted long-term inhibitory effects on the insulin receptor substrate-1 (IRS-1), GLUT4 and PPAR ${ }_{\gamma}$, which impaired insulin signaling and action. Kv1.3 is also involved in the regulation of synthesis and secretion of inflammatory cytokines, thereby affecting the specific immune responsiveness. Selective inhibition of Kv1.3 activity led to a reduction in the production of IL- 6 and TNFa and in $\mathrm{Ca}^{2+}$ influx, improving the inflammatory reaction that is an important pathogenesis of insulin resistance in type 2 diabetes $^{[20,34]}$.

It is well known that vascular diseases are the most common complications of diabetes. Vascular smooth muscle cell (VSMC) dysfunction, hypercoagubility and inflammation are the key factors in the etiology of vascular complications in diabetes $^{[35,36]}$. Recent studies have found that the functional expression of Kv1.3 is increased in proliferating VSMC and the selective blockade of Kv1.3 currents by margatoxin decreased 
the migration and proliferation of VSMC ${ }^{[37]}$. These results indicated that Kv1.3 is involved in the proliferative response of VMSC. Considering the fact that the major features of abnormal VSMC functions in diabetes include abnormal growth, proliferation and hypertrophy of VSMC, therefore, targeting the Kv1.3 channel represents a promising approach to treating vascular disorders in diabetes. In addition, the dysfunction of platelets is regarded as an important factor in the pathophysiology of vascular disease in diabetes ${ }^{[36]}$. Recent study has shown that Kv1.3 is the exclusive $\mathrm{Kv}$ channel in platelets, which sets the resting membrane potential, regulates $\mathrm{Ca}^{2+}$ signaling and influences the circulating platelet number ${ }^{[38]}$. Kv1.3 may play a potential role in the development of vascular complications in diabetes, and the therapeutic significance of Kv1.3 could be expanded to the treatment and prevention of diabetic vascular complications. Therefore, a drug-targeted Kv1.3 channel may have a therapeutic advantage over conventional therapies in that the Kv1.3 channel blocker stabilizes cellular function by regulating the membrane potential and the resultant intracelluar $\mathrm{Ca}^{2+}$ influx that influences multiple signal transduction pathways and cellular events, regardless of the etiology of cellular dysfunction.

\section{Future study}

Recently, a number of drugs have been shown to regulate the functional ion channel expression on cell membranes by regulating the channel trafficking pathways in addition to affecting the ion permeability of channels upon chronic administration $^{[39]}$. Also, the densities of several cardiac $\mathrm{Kv}$ channel genes are reportedly significantly altered in some pathologic conditions such as atrial fibrillation and heart failure. For example, in cases of chronic atrial fibrillation, there is a reduction in Kv1.5 protein levels and a decrease in current density, although it is not clear that the reduction in Kv1.5 current density is directly caused by atrial fibrillation events ${ }^{[40]}$. Consistent with this view, mutations in the genes encoding sulfonylurea receptor can contribute to defective trafficking and function of the pancreatic $\mathrm{K}_{\mathrm{ATP}}$ channel and be linked to an impaired pancreatic $\beta$-cell response ${ }^{[41]}$. This finding has important pharmacological implications in that drugs could exhibit different sensitivities to normal or pathological situations $^{[42]}$. To the best of our knowledge, no data are available concerning Kv1.3 channel expression in diabetes. In future studies, it will be interesting to examine the regulation of Kv1.3 channel expression and the effect of several drugs on the activity and expression of Kv1.3 channels on the cell membrane of insulin-sensitive tissues in diabetic patients.

\section{Acknowledgements}

We thank Dr KACZMAREK (Department of Pharmacology, Yale University School of Medicine, USA) for the Kv1.3 transfected $\mathrm{CHO}$ cells. This work was supported by a grant from the Medical Research Center, Korea Science and Engineering Foundation, Republic of Korea (R13-2002-005-01002-0).

\section{References}

1 Rudy B. Diversity and ubiquity of K channels. Neuroscience 1988; 25: 729-49.

2 Snyders DJ. Structure and function of cardiac potassium channels. Cardiovasc Res 1999; 42: 377-90.

3 DeCoursey TE, Chandy KG, Gupta S, Cahalan MD. Voltage-gated $\mathrm{K}^{+}$ channels in human T lymphocytes: a role in mitogenesis? Nature 1984; 307: 465-8.

4 MacDonald PE, Ha XF, Wang J, Smukler SR, Sun AM, Gaisano HY, et al. Members of the $\mathrm{Kv} 1$ and $\mathrm{Kv} 2$ voltage-dependent $\mathrm{K}^{+}$channel families regulate insulin secretion. Mol Endocrinol 2001; 15: 142335.

5 Burg ED, Remillard CV, Yuan JX. $\mathrm{K}^{+}$channels in apoptosis. J Membr Biol 2006; 209: 3-20.

6 Proks P, Lippiat JD. Membrane ion channels and diabetes. Curr Pharm Des 2006; 12: 485-501.

7 Cook DL, Hales CN. Intracellular ATP directly blocks $\mathrm{K}^{+}$channels in pancreatic B-cells. Nature 1984; 311: 271-3.

8 Drews G, Krippeit-Drews P, Dufer M. Electrophysiology of islet cells. Adv Exp Med Biol 2010; 654: 115-63.

9 Renstrom E, Barg S, Thevenod F, Rorsman P. Sulfonylurea-mediated stimulation of insulin exocytosis via an ATP-sensitive $\mathrm{K}^{+}$channelindependent action. Diabetes 2002; 51 (Suppl 1): S33-6.

10 Tabcharani JA, Misler S. $\mathrm{Ca}^{2+}$-activated $\mathrm{K}^{+}$channel in rat pancreatic islet $B$ cells: permeation, gating and blockade by cations. Biochim Biophys Acta 1989; 982: 62-72.

11 Henquin JC. Role of voltage- and $\mathrm{Ca}^{2+}$-dependent $\mathrm{K}^{+}$channels in the control of glucose-induced electrical activity in pancreatic B-cells. Pflugers Arch 1990; 416: 568-72.

12 Philipson LH, Hice RE, Schaefer K, LaMendola J, Bell GI, Nelson DJ, et al. Sequence and functional expression in Xenopus oocytes of a human insulinoma and islet potassium channel. Proc Natl Acad Sci USA 1991; 88: 53-7.

13 Tamarina NA, Kuznetsov A, Fridlyand LE, Philipson LH. Delayedrectifier (KV2.1) regulation of pancreatic beta-cell calcium responses to glucose: inhibitor specificity and modeling. Am J Physiol Endocrinol Metab 2005; 289: E578-85.

$14 \mathrm{Xu}$ J, Koni PA, Wang P, Li G, Kaczmarek L, Wu Y, et al. The voltagegated potassium channel Kv1.3 regulates energy homeostasis and body weight. Hum Mol Genet 2003; 12: 551-9.

15 Tschritter O, Machicao F, Stefan N, Schafer S, Weigert C, Staiger H, et al. A new variant in the human Kv1.3 gene is associated with low insulin sensitivity and impaired glucose tolerance. J Clin Endocrinol Metab 2006; 91: 654-8.

16 Doczi MA, Morielli AD, Damon DH. Kv1.3 channels in postganglionic sympathetic neurons: expression, function, and modulation. Am J Physiol Regul Integr Comp Physiol 2008; 295: R733-40.

17 Tucker K, Overton JM, Fadool DA. Kv1.3 gene-targeted deletion alters longevity and reduces adiposity by increasing locomotion and metabolism in melanocortin-4 receptor-null mice. Int J Obes (Lond) 2008; 32: 1222-32.

18 Baskin DG, Figlewicz Lattemann D, Seeley RJ, Woods SC, Porte D Jr, et al. Insulin and leptin: dual adiposity signals to the brain for the regulation of food intake and body weight. Brain Res 1999; 848: 114-23.

19 Fadool DA, Levitan IB. Modulation of olfactory bulb neuron potassium current by tyrosine phosphorylation. J Neurosci 1998; 18: 6126-37.

20 Xu J, Wang P, Li Y, Li G, Kaczmarek LK, Wu Y, et al. The voltage-gated potassium channel Kv1.3 regulates peripheral insulin sensitivity. Proc Natl Acad Sci USA 2004; 101: 3112-7. 
21 Li Y, Wang P, Xu J, Desir GV. Voltage-gated potassium channel Kv1.3 regulates GLUT4 trafficking to the plasma membrane via a $\mathrm{Ca}^{2+}$ dependent mechanism. Am J Physiol Cell Physiol 2006; 290: C34551.

22 Breum L, Bjerre U, Bak JF, Jacobsen S, Astrup A. Long-term effects of fluoxetine on glycemic control in obese patients with non-insulindependent diabetes mellitus or glucose intolerance: influence on muscle glycogen synthase and insulin receptor kinase activity. Metabolism 1995; 44: 1570-6.

23 Choi JS, Hahn SJ, Rhie DJ, Yoon SH, Jo YH, Kim MS. Mechanism of fluoxetine block of cloned voltage-activated potassium channel Kv1.3. J Pharmacol Exp Ther 1999; 291: 1-6.

24 Desir GV. Kv1.3 potassium channel blockade as an approach to insulin resistance. Expert Opin Ther Targets 2005; 9: 571-9.

25 Valverde P, Kawai T, Taubman MA. Potassium channel-blockers as therapeutic agents to interfere with bone resorption of periodontal disease. J Dent Res 2005; 84: 488-99.

26 Beeton C, Wulff H, Standifer NE, Azam P, Mullen KM, Pennington MW, et al. Kv1.3 channels are a therapeutic target for T cell-mediated autoimmune diseases. Proc Natl Acad Sci USA 2006; 103: 17414-9.

$27 \mathrm{Hu} \mathrm{X,} \mathrm{Xu} \mathrm{C,} \mathrm{Cong} \mathrm{Y.} \mathrm{Kv1.3} \mathrm{channel} \mathrm{as} \mathrm{a} \mathrm{promising} \mathrm{therapeutic} \mathrm{target}$ for acquired aplastic anemia. Med Hypotheses 2008; 70: 1072.

28 Bradding $\mathrm{P}$, Wulff $\mathrm{H}$. The $\mathrm{K}^{+}$channels $\mathrm{K}(\mathrm{Ca}) 3.1$ and $\mathrm{K}(\mathrm{v}) 1.3$ as novel targets for asthma therapy. Br J Pharmacol 2009; 157: 1330-9.

29 Wagstaff AJ, Goa KL. Rosiglitazone: a review of its use in the management of type 2 diabetes mellitus. Drugs 2002; 62: 1805-37.

30 Ahn HS, Kim SE, Jang HJ, Kim MJ, Rhie DJ, Yoon SH, et al. Open channel block of Kv1.3 by rosiglitazone and troglitazone: Kv1.3 as the pharmacological target for rosiglitazone. Naunyn Schmiedebergs Arch Pharmacol 2007; 374: 305-9.

31 Lee K, Ibbotson T, Richardson PJ, Boden PR. Inhibition of $K_{A T P}$ channel activity by troglitazone in CRI-G1 insulin-secreting cells. Eur J Pharmacol 1996; 313: 163-7.

32 Kern PA, Saghizadeh M, Ong JM, Bosch RJ, Deem R, Simsolo RB. The expression of tumor necrosis factor in human adipose tissue. Regulation by obesity, weight loss, and relationship to lipoprotein lipase. J Clin Invest 1995; 95: 2111-9.

33 Rotter V, Nagaev I, Smith U. Interleukin-6 (IL-6) induces insulin resistance in 3T3-L1 adipocytes and is, like IL-8 and tumor necrosis factor-alpha, overexpressed in human fat cells from insulin-resistant subjects. J Biol Chem 2003; 278: 45777-84.

34 Hotamisligil GS. The role of TNFalpha and TNF receptors in obesity and insulin resistance. J Intern Med 1999; 245: 621-5.

35 Hamet P, Sugimoto H, Umeda F, Franks DJ. Platelets and vascular smooth muscle: abnormalities of phosphodiesterase, aggregation, and cell growth in experimental and human diabetes. Metabolism 1983; 32 (7 Suppl 1): 124-30.

36 Morel O, Kessler L, OhImann P, Bareiss P. Diabetes and the platelet: Toward new therapeutic paradigms for diabetic atherothrombosis. Atherosclerosis 2010. doi: 10.1016/j.atherosclerosis.2010.03.019

37 Cidad P, Moreno-Dominguez A, Novensa L, Roque M, Barquin L, Heras $M$, et al. Characterization of ion channels involved in the proliferative response of femoral artery smooth muscle cells. Arterioscler Thromb Vasc Biol 2010; 30: 1203-11.

38 McCloskey C, Jones S, Amisten S, Snowden RT, Kaczmarek LK, Erlinge $\mathrm{D}$, et al. Kv1.3 is the exclusive voltage-gated $\mathrm{K}^{+}$channel of platelets and megakaryocytes: roles in membrane potential, $\mathrm{Ca}^{2+}$ signalling and platelet count. J Physiol 2010; 588: 1399-406.

39 Schumacher SM, McEwen DP, Zhang L, Arendt KL, Van Genderen KM, Martens JR. Antiarrhythmic drug-induced internalization of the atrialspecific K+ channel kv1.5. Circ Res 2009; 104: 1390-8.

40 Van Wagoner DR, Pond AL, McCarthy PM, Trimmer JS, Nerbonne JM. Outward $\mathrm{K}^{+}$current densities and $\mathrm{Kv1.5}$ expression are reduced in chronic human atrial fibrillation. Circ Res 1997; 80: 772-81.

41 Cartier EA, Conti LR, Vandenberg CA, Shyng SL. Defective trafficking and function of $K_{\text {ATP }}$ channels caused by a sulfonylurea receptor 1 mutation associated with persistent hyperinsulinemic hypoglycemia of infancy. Proc Natl Acad Sci USA 2001; 98: 2882-7.

42 Yan F, Lin CW, Weisiger E, Cartier EA, Taschenberger G, Shyng SL. Sulfonylureas correct trafficking defects of ATP-sensitive potassium channels caused by mutations in the sulfonylurea receptor. J Biol Chem 2004; 279: 11096-105. 